\section{English not Latin in botanical reports}

The decision at last year's International Botanical Congress to allow the use of either Latin or English for botanical descriptions and diagnoses was hailed as a triumph by the community. The ruling came into effect from 1 January 2012, but many botanists persist in using Latin.

There may be an element of understandable cultural resistance to changing to English. But most scientific journals are English-language publications, and there would seem to be no scientific reason for using Latin - it does not aid clarity or accuracy. It may have been effective for communication centuries ago, but now it has gone the way of the dodo.

The huge amount of literature that contains first-species descriptions in Latin poses a big challenge for translators, but that is no reason to compound the problem by continuing to use this ancient language. Instead, linguaphiles could deploy their skills by editing the computergenerated translations used for online botanical descriptions and books, creating a legacy rather than a liability.

English-language journals could contribute by asking for botanical diagnoses (explanations of how new taxa differ from their relatives) and descriptions to be in English not Latin. Botanists would then be freed up to study the world's flora and help land and natural-resource managers to make informed decisions. Frank Udovicic National Herbarium of Victoria, Royal Botanic Gardens Melbourne, South Yarra, Victoria, Australia. frank.udovicic@rbg.vic.gov.au

\section{Thousand-citation papers are outliers}

Joshua Nicholson and John Ioannidis suggest that the US National Institutes of Health (NIH) is failing to fund the most
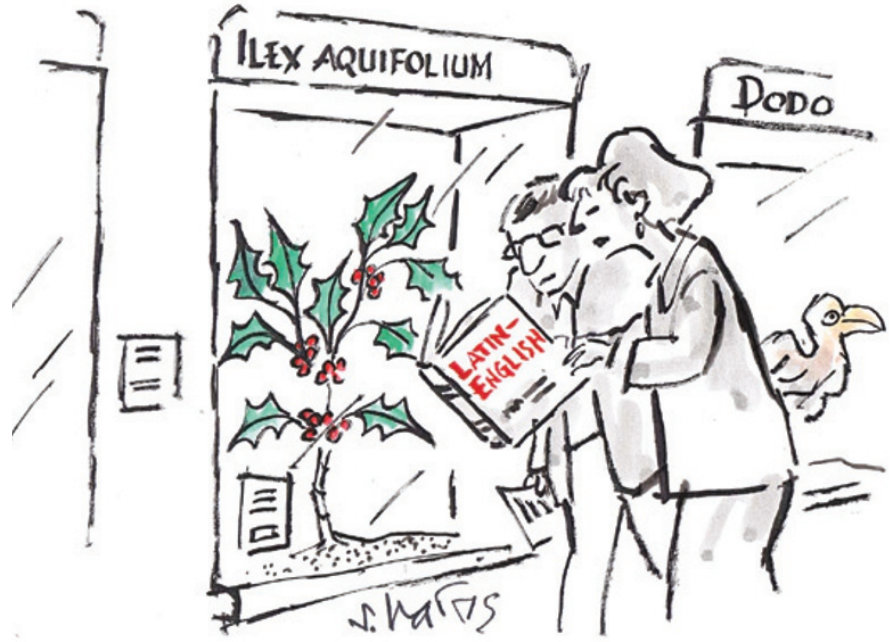

impactful researchers in favour of more conformist scientists with interests similar to those of the grant reviewers (Nature 492, 34-36; 2012). For presumably practical reasons, Nicholson and Ioannidis define these highimpact scientists as authors of a paper(s) with at least 1,000 citations. But setting the bar so high could yield unrepresentative outliers in the analysis.

Many of these authors are unlikely to repeat this level of impact consistently, so their papers become anecdotal rarities and atypical of career performance. And as the Comment revealed, several authors of papers with 1,000 or more citations had varied and justifiable explanations for not holding NIH funding. Also, agencies such as the Howard Hughes Medical Institute skim off some of the high-performing researchers, effectively removing them from the NIH system because they are considered to be well funded.

There can be network or familiarity bias among grant reviewers towards certain applicants, often for legitimate reasons - such as when an applicant's proposal might benefit from wider collaboration. Indeed, a junior investigator could find it productive to participate in a grant-panel study section, in which he or she can be exposed to new ideas and learn from peers.

Lunenfeld Research Institute,

Mount Sinai Hospital, Toronto,

Ontario, Canada.

woodgett@lunenfeld.ca

\section{Invest proceeds of 4G sale in UK science}

Earlier this month the

UK government pledged

$\mathfrak{E 6 0 0}$ million (US\$968 million)

to science projects in

recognition of the country's need to develop a more high-tech economy to promote sustainable growth. The Campaign for Science and Engineering (CaSE) and the UK charity Nesta are urging the government to supplement this investment with the $£ 4$ billion it is shortly due to receive from the sale of the $4 \mathrm{G}$ radio spectrum, which will revolutionize broadband speeds for mobile devices.

Our 4Growth public petition to reinvest this windfall in science and technology (see its4growth.co.uk and go.nature.com $/ \mathrm{kft} 87 \mathrm{z}$ ) has already collected almost 2,000 signatures, and has attracted widespread support from politicians and scientists.

To drive technological progress, 4Growth makes detailed recommendations for targeted investment in
James Woodgett Samuel people and skills, research infrastructure and commercial scientific enterprises.

This would be a handsome return on the efforts of innovators such as James Clerk Maxwell, Tim Berners-Lee, Guglielmo Marconi and John Logie Baird, without whom we wouldn't even be using $4 \mathrm{G}$ technology - let alone raising money from it.

Imran Khan Campaign for Science and Engineering, London, UK.

imran@sciencecampaign.org.uk Stian Westlake Nesta, London, UK.

\section{Cite links to data in reference lists}

A huge amount of work goes into creating data sets. It is crucial that these data, big or small, should be more prominently linked to their associated research articles as standard practice.

To achieve this, data can be cited directly in a publication's reference section using a permanent identifier such as a digital object identifier (DOI; see, for example, go.nature. com/vnyidi and go.nature.com/ $\mathrm{zdfbcl}$ ). So far, however, only very few journals do this.

Publishers, funders, researchers and institutions all need to recognize that data sets constitute a valuable scholarly resource. Authors should be credited for these career-making contributions. Enhanced dataset visibility would also benefit referees and readers by raising standards of data analysis, promoting more detailed review, encouraging data curation and boosting reproducibility and data reuse.

Laurie Goodman GigaScience, BGI, Hong Kong, China.

Rebecca Lawrence $F 1000$

Research, Faculty of 1000,

London, UK.

rebecca.lawrence@f1000.com

Kevin Ashley Digital Curation Centre, University of Edinburgh, UK. 